\title{
Development Strategic Research on Mountainous Ethnic Minority Beautiful Towns and Villages-Taking the Thousand Miao Villages Xijiang as Example
}

\author{
Danqing $\mathrm{Pu}^{1, \mathrm{a}}$, Ying $\mathrm{Cao}^{2, \mathrm{~b}}{ }^{*}$ Jiawen $\mathrm{Hou}^{3, \mathrm{c}}$ and Pengfei Qiu ${ }^{4, \mathrm{~d}}$ \\ ${ }^{1}$ Urban and Rural Development College, Sichuan Agricultural University, 288\# Jianshe Road, Du \\ Jiangyan, Sichuan Province, China \\ ${ }^{2}$ Urban and Rural Development College, Sichuan Agricultural University, 288\# Jianshe Road, Du \\ Jiangyan, Sichuan Province, China \\ ${ }^{3}$ Urban and Rural Development College, Sichuan Agricultural University, 288\# Jianshe Road, Du \\ Jiangyan, Sichuan Province, China \\ ${ }^{4}$ Bazhong Urban Planning Bureau, 160\# Jiangbei Avenue, Bazhong, Sichuan Province, China

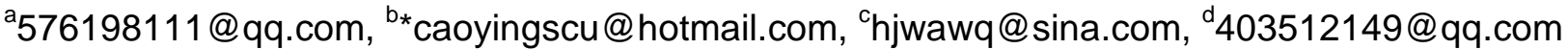

Keywords: Mountainous, Ethnic Minority, Beautiful Villages, Development Strategy

Abstract. In recent years, the development of the mountainous ethnic minority beautiful towns and villages has drawn people's attention. This paper took the thousand Miao villages Xijiang as an example, studied and analyzed the development strategic on mountainous ethnic minority beautiful towns and villages. Results show that the importance of planning which should be integrated to advance and guide the development of mountainous ethnic minority beautiful towns and villages in rational spatial layout. In the background of new urbanization, combined with regional economic development, mountainous ethnic minority beautiful towns and villages should be under the protection. While protecting ethnic minority village features, attention should be also paid to the development of pillar industries. To the mountainous ethnic minority villages, the first thing should be emphasizing planning's guidance and coordination, livable industry planning and construction mode, which is an important strategic choice to achieve its sustainable development.

\section{Introduction}

The academician Liangyong $\mathrm{Wu}$ proposed that 'In the rapid urbanization process, the accumulation of experience and researches is difficult to cope with the reality of demand. The theories and practice about the construction of human settlements in hilly areas are faced dramatic demand. Therefore, to explore more about the mountainous cities, we should propose a particular research orientation and build up a special research team' ${ }^{[1]}$.

In the mountainous region, rich in energy, minerals, hydro energy, and variety of ecological resources are effective force of its development. So the problem remains to be solved is how to properly use, exploit and protect these resources. However, due to particularities of mountainous region, development pattern in accordance with the local situations and scientific strategies should be proposed to take advantages of the local environment ${ }^{[1]}$.

\section{Current situation of Thousand Miao Villages Xijiang}

Connected by a dozen natural hillside villages into a film, thousand Miao villages Xijiang is the largest inhabited by the Hmong village in china, even in the world. Its location is typical of the river valley, the Miao villagers opened up a lot of terraces at its upstream. Due to restrictions by the arable land resources, the villagers living here full advantage of terrain features here. They built on Diaojiao in the mid unique, laid the foundation for the development of local tourism. Since 1995 thousand Miao Villages Xijiang tourism developments has been financial supported by the government, the development of Miao Villages officially launched. In the past more than ten years, a large number of 
tourists come here especially promoted the development of tourism Miao Village. However, due to the local government lack of management and construction's experience, the development of project with development of the characteristics villages planning is missing some advanced and guidance. Lacking of awareness of the protection of cultural and architectural features characteristic of, tourism resources income is also a certain degree of leakage.

\section{Development Strategy}

Combining with the background of regional economic development, to achieve priority and guidance of planning. The ethnic minority towns and villages mainly located in under developed mountainous regions, adapting and coordinating artificial mountain building and the mountain environment reflect the importance of the relationship between man and nature's ecological balance ${ }^{[2]}$. Therefore, to build mountainous ethnic minority beautiful towns and villages in the context of the development of regional economy and achieve planning's advanced and guidance are important. When construction is implemented, the ecology should be protected, and the importance of sustainable development should not be ignored. To guide the development of Miao Villages by priority design planning combined with the characteristics of the Miao Village building. Build a long-term development of meaningful for other features Villages by implemented the scientific development and provided a model for other similar villages development. To correctly treat the development of characteristic villages, it is necessary to form a healthy circle model - utilization before development, protection before utilization and development in protection.

Unified planning and rational layout. Thousand Miao villages Xijiang locates in mountainous region where take agriculture as the body of county economy. Due to the lack of scientific planning, many of the farmlands along the river were transformed into riverfront landscapes and performance arenas, which have an influence on residents' daily life to some extent. Thus it's obvious that, the development lacking in scientific planning and rational layout will not last long. Therefore, a suitable development strategy should be propose for the thousand Miao villages Xijiang district and strengthened the integrity of spatial arrangement. Only in this way, the village development can be stable and rapid. It must be combined with the special nature of the mountainous region to specify for the policy and direction for its development. Lacking a government's unified planning, blinding self-transformation houses by the villagers to follow the development trend, sacrificing natural resources to achieve their own needs, would only drive the development of features Villages to death day by day. Without rational distribution of government, the development of feature villages would become as maze.

Emphases the planning and construction mode of habitability and industry. Due to the insufficient economic conditions and vulnerable infrastructure of mountain areas, the development rate of economy, science and cultural are relative slow to other regions. Combined with issues such as backwardness technological level, lack of technical personnel, destroyed the environment and ecology, all of them became the mountain economic development and town construction obstacles ${ }^{[3]}$.

Therefore, planning should be objective analyzed of the urgent problem by clear development goals, emphasis planning and development of Habitability and industry, implement a series of policies and measures, improve quality of service level, protect the natural ecological resources without further damage to make the villagers to obtain the economic benefits from the development and also inherit the characteristic custom and cultural of villages. The good living environment would not only improve the living conditions for local residents, but also provide and keep the ethnic features as tourism resources to attract more tourists to provide local jobs. Rich in ecological resources, mountain areas offer favorable conditions for constructing human settlements and have advantages of developing tourism. Interact with each other during the development of Habitability and industry.

Emphasis on the development of pillar industries. Due to thousand Miao villages Xijiang's natural conditions, it was developed relatively late to other areas. However, the relative late development brings the more original folk customs which were popular to tourists to experiences. 
Based on this advantage, the development of tourism has become the first choice of its villagers to get rich. Thousand Miao Villages Xijiang tourism development to local villagers brought enormous economic benefits, which has been shown in Table 1:

Table 1 Leishan County in Guizhou Province 2006-2009 farmers' income and the number of tourists and income

\begin{tabular}{lcccc}
\hline \multicolumn{1}{l}{ Years } & 2006 & 2007 & 2008 & 2009 \\
\hline $\begin{array}{l}\text { Rural per capita net income } \\
\text { [RMB] }\end{array}$ & 1706 & 1928 & 2257 & 2489 \\
$\begin{array}{l}\text { Rural residents per capita } \\
\text { disposable income [RMB] }\end{array}$ & 1682.85 & 1897.4 & 2181 & 2315.7 \\
& & & & \\
$\begin{array}{l}\text { Tourist direct income [million] } \\
\text { Tourist trips [million] }\end{array}$ & 0.4154 & 1.1 & 2.58 & 5.30 \\
\hline
\end{tabular}

Note: The table data from the literature ${ }^{[4]}$

However, the concept of tourism development makes the residents have a strong sense of rushing for wealth. They spare no effort to pursue the wealth by destroys to the environment. However, they ignore the importance of sustainable development which is the foundation of their living and development. With economic development, industrial structure of thousand Miao villages Xijiang has gradually evolved from a single agricultural production as a supplement to the tourism industry, agricultural. However, due to the local government lack of scientific guidance and attention, leading to some problems, such as development of its tourism industry Over-reliance on government business, significant degrade of development and innovation, relatively wreaked developed by the project to attract the tourists, unable to extend the stay time of visitors and other problems. Due to the dominant local villagers in the development of its tourism industry, the performances, commentary, guides, etc. have to be done by, But because the villagers suffered cultural level is not high, it is often difficult to complete the work, resulting investors understand the cultural characteristics of the regions not deep enough, thorough enough. Therefore, when developing and building characteristics villages, construction should be based on the unique local to regional, the current situation of the development of folk characteristics, considering the special characteristics of ethnic customs and topography, comply with the requirements of its construction, attention to the development of pillar industries, focus on training local talent, to formulate the development route for science. Rather than blindly follow the changes of the economy, development and introduction of the project should primarily consider the importance of sustainable development.

Strengthening the protection of ethnic culture and featured architecture. The construction of the minority villages should keep up with the current economic situation, and the ecological resources and historical relics should be used and protected properly. Where the Thousand Miao villages Xijiang peoples locates in is a typical river valley, and over 1200 Diaojiao buildings are built on steep hills at about 70 degrees. Because of their locations, the Diaojiao buildings are very spectacular and get the title treasures of ethnic architecture. Extremely rich ethnic customs, ethnic programs, folk dance, Miao clothing, food, language, silver, and other traditions should be preserved the integrity and unique. However, due to some villagers' pursuit of wealth, many stilted buildings are rebuilt as modern hotels. The traditional buildings disappeared one by one. For example, the stilted buildings should be maintained to convey the ethnic history and characteristics to people. With the society developing, the protection of featured materials and buildings is an extremely urgent affair. Local construction characteristics should be fully considered when there is development and innovation of construction without any distort. Continuous improvement in the development of mechanisms for its protection while enhancing features Combined with the characteristics of mountain regions, to develop the mountain characteristics of the buildings and cultural should be considered as the priority of planning and development. Characteristics, progress in development, summarized in progress. 


\section{Summary}

In recent years, mountainous ethnic minority beautiful towns and villages received widespread attention and discussion, but to implement and upgrade to a new level of development there are still some problems. This paper took the thousand Miao villages Xijiang as an example. To correctly treat the development of mountainous ethnic minority beautiful towns and villages in the background of new urbanization and combined with regional economic development Attention to the development of pillar industries and protect minority ethnic village characteristics. while emphasizing planning's guidance and coordination of planning and developing Habitability and industry and planning and construction mode, as a brief analysis, But to efficient use in mountainous ethnic minority beautiful towns and villages construction will be further studied.

\section{Acknowledgements}

This work was financially supported by the Sichuan Center for Rural Development Research Science Foundation (CR1204), the Sichuan Education Department of Sichuan Province Science Foundation (13ZB0277), the Sichuan Agricultural University of Federation of Social Sciences Circle Social Science Foundation (xck201207), the Sichuan Agricultural University of Research Interest Training Program (2014332) and the Sichuan Agricultural University of Students Innovation Experiment Program (201410626090).

\section{References}

[1] Wu Liangyong, Studies on Mountain Human Settlements [J] Journal of Human Settlements in West China 2014, 29 (04): 1-3.

[2] Zhao Waning, Sciatic Connotations of Mountain Urban and Rural Planning-The Academic Statements in the Launch Conference of Academic Committee of Mountain Urban and Rural Planning, Urban Planning Society of China [J] Journal of Human Settlements in West China 2014,29 (04) : 4-9.

[3] Liu Xiaorong, Research on Sustainable Development of Tourism in Ethnic Village Based on The Cultural Capital Theory [D] A Dissertation Submitted to China University of Geosciences for The Doctor Degree of Resource Industry \& Economics.

[4] Chen Lily, Deng Jibe, Chen Xiangzheng, On Villager's Profit Distribution from Exploitation of National Villages_-Taking the Miao Village in Xining as an example [A] .1007-8592 (2011): 10-0062-06. 